OPEN ACCESS

Edited by:

Jiang Ma,

Shenzhen University, China

Reviewed by:

Ran Li,

Beihang University, China

Baoan Sun,

Institute of Physics (CAS), China

${ }^{*}$ Correspondence:

Z. L

Iz_kevin@163.com

K. F. Yao

kfyao@tsinghua.edu.cn

Specialty section:

This article was submitted to

Ceramics and Glass,

a section of the journal

Frontiers in Materials

Received: 30 October 2021 Accepted: 19 November 2021

Published: 05 January 2022

Citation:

Li Z, Yao KF, LiU TC, LiX and Wang S (2022) Effect of Annealing on the

Magnetic Properties of

FeCoNiCuNbSiB Soft Magnetic Alloys.

Front. Mater. 8:805609.

doi: 10.3389/fmats.2021.805609

\section{Effect of Annealing on the Magnetic Properties of FeCoNiCuNbSiB Soft Magnetic Alloys}

\author{
Z. $\mathrm{Li}^{1 *}$, K. F. Yao ${ }^{2 *}$, T. C. $\mathrm{Liu}^{3}, \mathrm{X} . \mathrm{Li}^{1}$ and S. Wang ${ }^{1}$
}

${ }^{1}$ Institute of High Energy Physics, Chinese Academy of Science, Beijing, China, ${ }^{2}$ School of Material Science and Engineering, Tsinghua University, Beijing, China, ${ }^{3}$ China Iron and Steel Research Institute Group, Advanced Technology and Materials Co., Ltd., Beijing, China

A series of nanocrystalline soft magnetic alloys with nominal compositions of $\mathrm{Fe}_{66.8-\mathrm{x}} \mathrm{Co}_{10} \mathrm{Ni}_{\mathrm{x}} \mathrm{Cu}_{0.8} \mathrm{Nb}_{2.9} \mathrm{Si}_{11.5} \mathrm{~B}_{8}(\mathrm{x}=1-15$ at\%) were developed and studied. Effects of annealing on the soft magnetic properties, crystallization behavior, and domain structure were investigated. The alloys with higher $\mathrm{Ni}$ content were prone to exhibit stronger magnetic anisotropy. The $\mathrm{Fe}_{66.8} \mathrm{Co}_{10} \mathrm{Ni}_{10} \mathrm{Cu}_{0.8} \mathrm{Nb}_{2.9} \mathrm{Si}_{11.5} \mathrm{~B}_{8}$ alloy exhibited excellent soft magnetic properties, including the low permeability of 2000 , low coercivity of about $0.6 \mathrm{~A} / \mathrm{m}$, and low remanence of $2.4 \mathrm{mT}$, together with a temperature gap of $128 \mathrm{~K}$ between two crystallization onset temperatures. It has been found that the $\mathrm{Ni}$ content and the annealing process possess significant effects on the soft magnetic property of the nanocrystalline alloys. It shows that the developed $\mathrm{Fe}_{66.8} \mathrm{CO}_{10} \mathrm{Ni}_{10} \mathrm{Cu}_{0.8} \mathrm{Nb}_{2.9} \mathrm{Si}_{11.5} \mathrm{~B}_{8}$ nanocrystalline alloy exhibits great potentials for applying in the field of common mode chokes or current transformers, due to its ability to resist the direct current.

Keywords: nanocrystallization, annealing, microstructure, soft magnetic properties, magnetic domain

\section{INTRODUCTION}

FINEMET-type FeCuNbSiB nanocrystalline alloys exhibit excellent comprehensive soft magnetic properties including high saturation magnetic induction $B_{s}$, high permeability $\mu$, and low core loss $P$ (Yoshizawa et al., 1988a). Furthermore, since FINEMET-type FeCuNbSiB nanocrystalline alloys can be easily prepared in air at low cost, they are widely used in electronic fields such as high-frequency power transformers, common mode chokes, magnetic amplifiers, and current transformers (Yoshizawa et al., 1988b; Petzold, 2002; Hasegawa, 2004; Herzer et al., 2005; Hasegawa, 2006; Herzer, 2013). Nowadays, the devices used in electronic and information fields, however, are prone to higher power and higher frequency. Then, it is necessary to develop soft magnetic materials with better permeability properties in high-frequency range and good DC resistance ability.

It is known that the performance of permeability vs. frequency in high-frequency regions could be enhanced by a large anisotropy constant $K_{u}$ when the coercivity property does not deteriorate. This results in the decreases in permeability attenuation with frequency. This characteristic makes the design of the LCR rectifier circuit become easier when the material is processed into an inductor. The anisotropy constant $K_{u}$ could be evaluated by Herzer et al. (2011)

$$
K_{\mathrm{u}}=\frac{H_{k} J_{s}}{2}
$$


where $H_{k}$ is the magnetic anisotropy field and $J_{s}$ is the saturation magnetic polarization. As indicated by Eq. 1, the magnetic anisotropy constant $K_{u}$ can be improved by increasing $J_{s}$. Nevertheless, despite there being myriad works focusing on developing materials with high saturation magnetic polarization (Makino et al., 1995; Ohta and Yoshizawa, 2007; Makino et al., 2009; Kubota et al., 2011; Urata et al., 2011; Chen et al., 2013; Li et al., 2014; Li et al., 2015; Shi and Yao, 2020; Shi et al., 2021), few of these materials can meet the requirements of industrial mass production. Moreover, the increase in magnetic anisotropy constant $K_{\mathrm{u}}$ is very limited.

For FINEMET-type alloys, the magnetic field-induced anisotropy is very weak (Herzer, 1994a). However, it was found that the creep could induce the anisotropy in FINEMET-type alloys (Herzer, 1994b). It shows a $K_{u}$ value as large as $1,000 \mathrm{~J} / \mathrm{m}^{3}$ can be achieved after the FINEMET-type alloys are annealed with a 100-MPa tensile stress applied along the ribbon axis. However, due to the low productivity, inducing anisotropy via creep is impractical for industrial production.

For nanocrystalline alloys processed by magnetic field annealing, adding other ferromagnetic elements such as Co and $\mathrm{Ni}$ is considered to be conducive to the induction of inplane anisotropy (Fujimori et al., 1977; Ohnuma et al., 2003; Yoshizawa et al., 2003). However, the crystallization process would be significantly influenced after the addition/ replacement of $\mathrm{Co}$ and $\mathrm{Ni}$ to Fe-based amorphous alloys (Agudo and Vázquez, 2005). The increment of the Ni content leads to the rise of the second crystallization peak temperature of the amorphous alloy rise, resulting in the deterioration of the thermal stability and soft magnetic property of the alloy. Then, understanding the factors affecting the crystallization behavior and soft magnetic property of the nanocrystalline alloy is important.

Here, effects of $\mathrm{Ni}$ addition and annealing process on the structure and properties of $\mathrm{FeCoNiCuNbSiB}$ soft magnetic alloys were investigated, and an $\mathrm{Fe}_{66.8} \mathrm{Co}_{10} \mathrm{Ni}_{10} \mathrm{Cu}_{0.8} \mathrm{Nb}_{2.9} \mathrm{Si}_{11.5} \mathrm{~B}_{8}$ nanocrystalline alloy with good soft magnetic property and large resistance to direct current in the high-frequency region was obtained.

\section{EXPERIMENTAL PROCEDURE}

Alloy ingots with a nominal composition of $\mathrm{Fe}_{66.8-\mathrm{x}}$ $\mathrm{Co}_{10} \mathrm{Ni}_{\mathrm{x}} \mathrm{Cu}_{0.8} \mathrm{Nb}_{2.9} \mathrm{Si}_{11.5} \mathrm{~B}_{8}$ ( $\mathrm{x}=1,5,10,15$ at $\left.\%\right)$ were prepared by induction melting in a high-vacuum condition. The raw materials were industrial-purity metals of $\mathrm{Fe}$ (99.9 mass\%), Co (99.9 mass\%), Ni (99.9 mass\%), Cu (99.9 mass\%), Si (99.9 mass $\%)$, pre-alloyed $\mathrm{Nb}-\mathrm{Fe}$ (99.7 mass\%), and Fe-B (99.7 mass\%). The amorphous ribbons were manufactured by the single-roll rapid solidification method. The ribbon width is $30 \mathrm{~mm}$, and thickness is $22 \mu \mathrm{m}$. The ribbons were slit to $6 \mathrm{~mm}$ in width. Toroidal cores with the outer diameter of $29 \mathrm{~mm}$ and inner diameter of $21 \mathrm{~mm}$ were wounded by these slit ribbons then. These cores were annealed at different temperatures in a furnace with $2 \mathrm{~L} / \mathrm{min}$ flowing argon; meanwhile, a 400-Oe transverse magnetic field

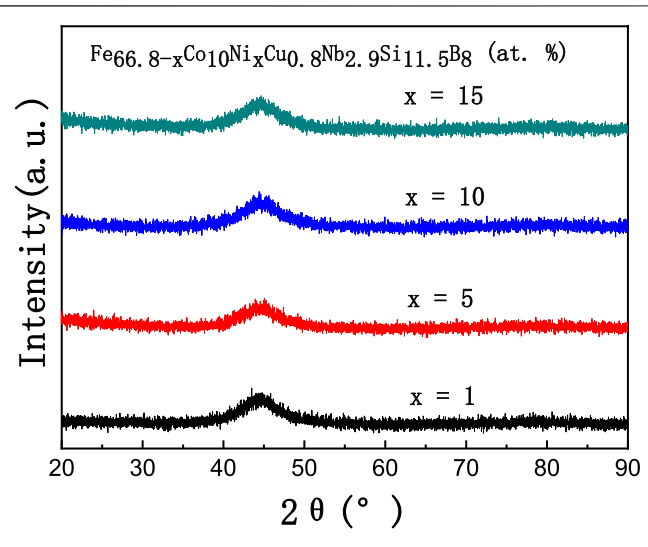

FIGURE 1 | XRD patterns of the as-cast $\mathrm{Fe}_{66.8-x} \mathrm{Co}_{10} \mathrm{Ni}_{x} \mathrm{Cu}_{0.8} \mathrm{Nb}_{2.9} \mathrm{Si}_{11.5} \mathrm{~B}_{8}$ $(x=1,5,10,15$ at\%) ribbons.

was applied. The transverse field means the direction is parallel to the axis of rotation.

The microstructure of as-cast and annealed ribbons was analyzed by X-ray diffractometry (XRD, Bruker D8 Advance) with $\mathrm{Cu} \mathrm{K}$ radiation $(\lambda=0.15406 \mathrm{~nm})$. The thermodynamic characteristics of the ribbons were analyzed by the differential scanning calorimeter (DSC, NETZSCH 404C) at a heating rate of $10 \mathrm{~K} / \mathrm{min}$ under high-purity argon flow. The B-H loops were measured by a static magnetic property analyzer (MATS2010SD). The core loss property of the cores was analyzed by the IWATSU B-H Analyzer. The test frequency range was $10-100 \mathrm{kHz}$, sinusoidal type. The maximum flux density values were 100,200 , and $300 \mathrm{mT}$, respectively. Images of the magnetic domain structures for samples with different compositions were captured using the magneto-optical Kerr microscope (Zeiss $\mathrm{A} \times 10$ ). All measurements were performed at room temperature.

\section{RESULTS AND DISCUSSION}

The XRD patterns of the as-cast $\mathrm{Fe}_{66.8-\mathrm{x}} \mathrm{Co}_{10} \mathrm{Ni}_{\mathrm{x}} \mathrm{Cu}_{0.8} \mathrm{Nb}_{2.9} \mathrm{Si}_{11.5} \mathrm{~B}_{8}$ $(\mathrm{x}=1,5,10,15$ at\%) ribbons are shown in Figure 1. Except for the broad peak corresponding to the amorphous phase, no crystallization peak can be found in the XRD patterns, indicating that the microstructure of the as-cast ribbons is amorphous.

The DSC curves of the as-cast $\mathrm{Fe}_{66.8 \text { - } \mathrm{x}}$ $\mathrm{Co}_{10} \mathrm{Ni}_{\mathrm{x}} \mathrm{Cu}_{0.8} \mathrm{Nb}_{2.9} \mathrm{Si}_{11.5} \mathrm{~B}_{8}(\mathrm{x}=1,5,10,15$ at\% $)$ ribbons are shown in Figure 2. The first and second crystallization onset temperature $T_{x 1}$ and $T_{x 2}$ and the first and second crystallization peak temperature $T_{1}$ and $T_{2}$ are indicated by arrows on the curves. We can find three distinguishing characteristics in the DSC curves. Firstly, $T_{2}$ decreases gradually with the increase in $\mathrm{Ni}$ content, while $T_{1}$ stays almost unchanged. The temperature gap $\Delta T_{x}\left(T_{x 2}-T_{x 1}\right)$ shrinks down from 165 to $119 \mathrm{~K}$ with the increase in $\mathrm{Ni}$ content. However, the interval $\Delta T_{x}$ for the alloys with $\mathrm{x}=5$, 10,15 are almost the same. This value agrees to the previous work by Agudo in Ref. (Agudo and Vázquez, 2005). Secondly, there is 

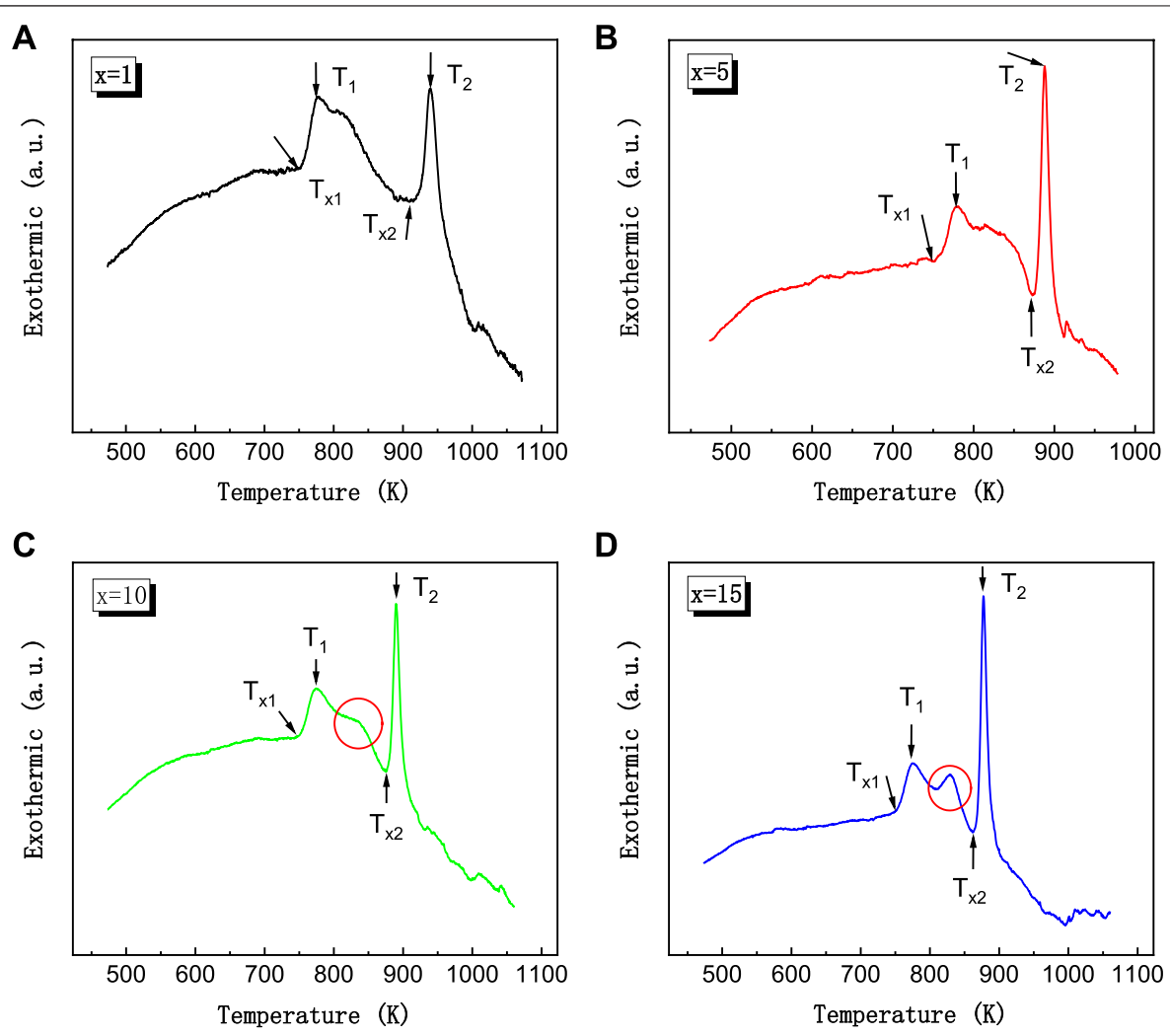

FIGURE 2 |DSC curves of the as-cast Fe ${ }_{66.8-x} \mathrm{Co}_{10} \mathrm{Ni}_{x} \mathrm{Cu}_{0.8} \mathrm{Nb}_{2.9} \mathrm{Si}_{11.5} \mathrm{~B}_{8}(\mathrm{x}=1,5,10,15$ at\%) ribbons at a heating speed of $10 \mathrm{~K} / \mathrm{min}$, (A) $\mathrm{x}=1$ alloy, (B) $\mathrm{x}=5$ alloy, (C) $x=10$ alloy, (D) $x=15$ alloy.

TABLE 1 | Thermodynamic data of as-cast $\mathrm{Fe}_{66.8-\mathrm{x}} \mathrm{Co}_{10} \mathrm{Ni}_{x} \mathrm{Cu}_{0.8} \mathrm{Nb}_{2.9} \mathrm{Si}_{11.5} \mathrm{~B}_{8}(\mathrm{x}=$ $1,5,10,15$ at\%) alloy ribbons.

\begin{tabular}{lccccc}
\hline Alloy & $\mathbf{T}_{\mathbf{x} \mathbf{1}}(\mathbf{K})$ & $\mathbf{T}_{\mathbf{1}}(\mathbf{K})$ & $\mathbf{T}_{\mathbf{x} \mathbf{2}}(\mathbf{K})$ & $\mathbf{T}_{\mathbf{2}}(\mathbf{K})$ & $\boldsymbol{\Delta} \mathbf{T}_{\mathbf{x}}(\mathbf{K})$ \\
\hline $\mathrm{X}=1$ & 757 & 779 & 922 & 940 & 165 \\
$\mathrm{X}=5$ & 759 & 780 & 878 & 888 & 119 \\
$\mathrm{X}=10$ & 752 & 774 & 880 & 890 & 128 \\
$\mathrm{X}=15$ & 750 & 777 & 869 & 877 & 119 \\
\hline
\end{tabular}

an exothermic-peak-like region between $T_{x 1}$ and $T_{x 2}$ at about $828 \mathrm{~K}$ for the alloys with $\mathrm{x}=10,15 \%$; this region is considered to be an overlap of the two stages of crystallization. It means that the alloys of $\mathrm{Fe}_{56.8} \mathrm{Co}_{10} \mathrm{Ni}_{10} \mathrm{Cu}_{0.8} \mathrm{Nb}_{2.9} \mathrm{Si}_{11.5} \mathrm{~B}_{8}$ and $\mathrm{Fe}_{51.8} \mathrm{Co}_{10} \mathrm{Ni}_{15} \mathrm{Cu}_{0.8} \mathrm{Nb}_{2.9} \mathrm{Si}_{11.5} \mathrm{~B}_{8}$ tend to get into the second crystallization process much more easily. Also, the stability of the first-stage crystallization phase is weaker. This might be the reason for the $\Delta T_{x}$ of the $10 \% \mathrm{Ni}$ alloy being a little larger than $5 \%$ $\mathrm{Ni}$ alloy. Values of $T_{x 1}, T_{x 2}, T_{1}, T_{2}$, and $\Delta T_{x}$ of the as-cast $\mathrm{Fe}_{66.8-\mathrm{x}}$ $\mathrm{Co}_{10} \mathrm{Ni}_{\mathrm{x}} \mathrm{Cu}_{0.8} \mathrm{Nb}_{2.9} \mathrm{Si}_{11.5} \mathrm{~B}_{8}$ alloys are summarized in Table 1.

The cores were annealed at $838 \mathrm{~K}$ with transverse magnetic field for 15, 30, and $45 \mathrm{~min}$, respectively. The B-H loops of the cores are shown in Figure 3. The hysteresis loops of the annealed alloys show good linearity. With the increment of Ni content, the anisotropic field $H_{k}$ rises from 200 to $380 \mathrm{~A} / \mathrm{m}$. The values of the magnetic anisotropy constant $K_{u}$ can be obtained from Eq. 1.
During the calculation of $K_{u}$, $J_{s}$ was estimated using the values of $B_{800}\left(B_{800}\right.$ denotes the magnetic induction intensity of alloys under an applied magnetic field of $800 \mathrm{~A} / \mathrm{m}$ ), and the $B_{800}$ values are $1.26,1.15,1.11$, and $1.04 \mathrm{~T}$ for the alloys of $\mathrm{Ni}=1 \%, \mathrm{Ni}=5 \%$, $\mathrm{Ni}=10 \%$, and $\mathrm{Ni}=15 \%$, respectively. When the $\mathrm{Ni}$ content increases to $15 \%$, the alloy exhibits a lower permeability and larger magnetic anisotropy field $H_{k}$. However, the coercivity of the alloy is significantly increased, and the linearity of the hysteresis loop gets worse. The coercivity $\left(H_{c}\right)$, remanence $\left(B_{r}\right)$, initial permeability $\left(\mu_{i}\right)$, and anisotropy constant $\left(K_{u}\right)$ properties are shown in Table 2 . With the prolongation of annealing time, the permeability of the alloy gradually decreases. The strength of the magnetic anisotropy field becomes stronger. Moreover, the ability to resist the external magnetic field is enhanced. The $H_{c}$ and $B_{r}$ for the $\mathrm{Fe}_{65.8} \mathrm{Co}_{10} \mathrm{Ni}_{1} \mathrm{Cu}_{0.8} \mathrm{Nb}_{2.9} \mathrm{Si}_{11.5} \mathrm{~B}_{8}$ alloy decrease with the increasing annealing time. The $H_{c}$ and $B_{r}$ of $\mathrm{Fe}_{61.8} \mathrm{Co}_{10} \mathrm{Ni}_{5} \mathrm{Cu}_{0.8} \mathrm{Nb}_{2.9} \mathrm{Si}_{11.5} \mathrm{~B}_{8}$ alloy increase firstly and then get smaller with the increase in heat treatment time. $H_{c}$ and $B_{r}$ increase definitely with the heat treatment time when the $\mathrm{Ni}$ content is high $(\mathrm{x}=10,15 \%)$. When the Ni content reaches $15 \%$, the coercive $H_{c}$ and the remanence $B_{r}$ increase greatly. When the heat treatment time increased from 15 to $45 \mathrm{~min}, H_{c}$ and $B_{r}$ increased from $15.81 \mathrm{~A} / \mathrm{m}$ and $28 \mathrm{mT}$ to $163.8 \mathrm{~A} / \mathrm{m}$ and $330 \mathrm{mT}$, respectively. With the increase in $\mathrm{Ni}$ content, the relative initial 

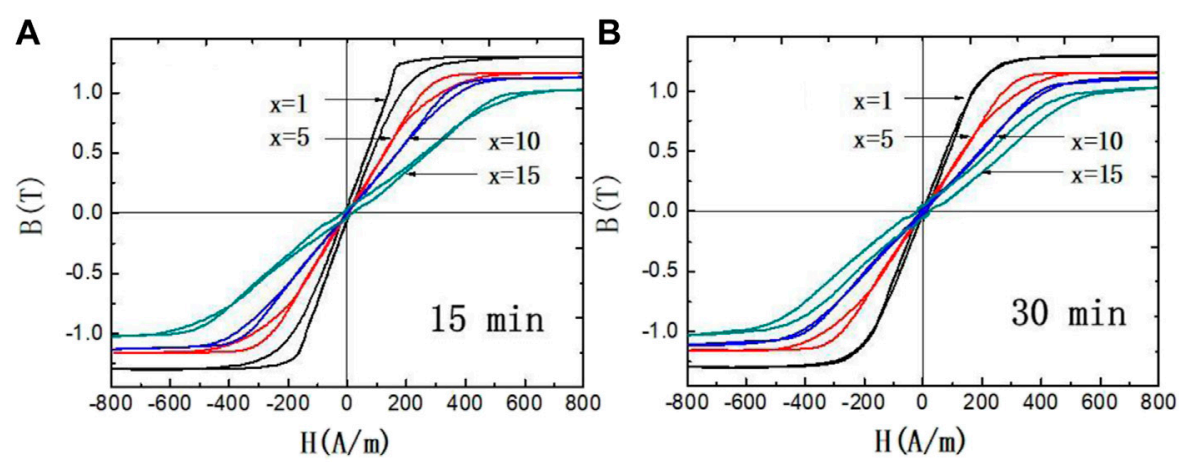

C

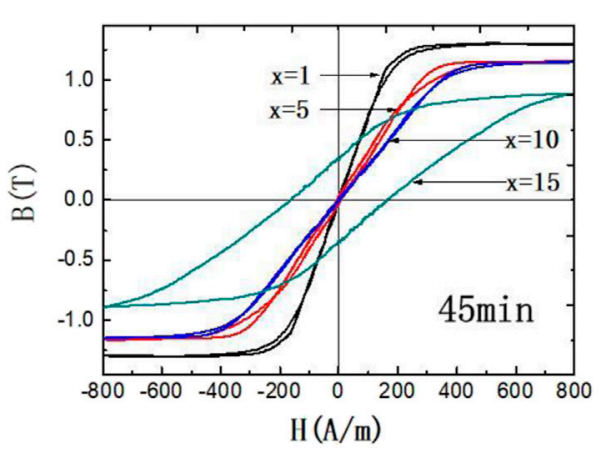

FIGURE 3 | B-H loops of $\mathrm{Fe}_{66.8-\mathrm{x}} \mathrm{Co}_{10} \mathrm{Ni}_{x} \mathrm{Cu}_{0.8} \mathrm{Nb}_{2.9} \mathrm{Si}_{11.5} \mathrm{~B}_{8}(\mathrm{x}=1,5,10,15$ at\%) cores annealed at $838 \mathrm{~K}$ for. (A) $15 \mathrm{~min}$, (B) $30 \mathrm{~min}$, and (C) $45 \mathrm{~min}$.

TABLE 2 | Magnetic properties of $\mathrm{Fe}_{66.8-\mathrm{x}} \mathrm{Co}_{10} \mathrm{Ni}_{\mathrm{x}} \mathrm{Cu}_{0.8} \mathrm{Nb}_{2.9} \mathrm{Si}_{11.5} \mathrm{~B}_{8}(\mathrm{x}=1,5,10$, 15 at\%) alloy cores.

\begin{tabular}{|c|c|c|c|}
\hline Alloys & $15 \mathrm{~min}$ & $30 \mathrm{~min}$ & $45 \mathrm{~min}$ \\
\hline \multicolumn{4}{|c|}{$\mathrm{H}_{\mathrm{c}}(\mathrm{A} / \mathrm{m})$} \\
\hline$x=1$ & 7.93 & 0.54 & 0.40 \\
\hline$x=5$ & 3.21 & 0.41 & 0.65 \\
\hline$x=10$ & 0.21 & 0.61 & 0.84 \\
\hline$x=15$ & 15.81 & 19.41 & 163.8 \\
\hline \multicolumn{4}{|l|}{$\mathrm{B}_{\mathrm{r}}(\mathrm{mT})$} \\
\hline$x=1$ & 55.71 & 30.55 & 23.92 \\
\hline$x=5$ & 31.91 & 23.41 & 23.88 \\
\hline$x=10$ & 2.35 & 2.35 & 7.44 \\
\hline$x=15$ & 27.6 & 63.2 & 329.5 \\
\hline \multicolumn{4}{|l|}{$\mu_{\mathrm{i}}$} \\
\hline$x=1$ & 5,300 & 5,100 & 5,400 \\
\hline$x=5$ & 3,050 & 2,940 & 2,660 \\
\hline$x=10$ & 2,290 & 2000 & 2,230 \\
\hline$x=15$ & 1,310 & 810 & 580 \\
\hline \multicolumn{4}{|c|}{$\mathrm{K}_{\mathrm{u}}\left(\mathrm{J} / \mathrm{m}^{3}\right)$} \\
\hline$x=1$ & 108 & 126 & 129 \\
\hline$x=5$ & 163 & 170 & 174 \\
\hline$x=10$ & 204 & 225 & 200 \\
\hline$x=15$ & 232 & 257 & 355 \\
\hline
\end{tabular}

permeability $\mu_{i}$ decreases and the magnetic anisotropy $K_{u}$ is enhanced.

The XRD patterns of $\mathrm{Fe}_{66.8-\mathrm{x}} \mathrm{Co}_{10} \mathrm{Ni}_{\mathrm{x}} \mathrm{Cu}_{0.8} \mathrm{Nb}_{2.9} \mathrm{Si}_{11.5} \mathrm{~B}_{8}(\mathrm{x}=1$, $5,10,15$ at\%) alloy ribbons which annealed at $838 \mathrm{~K}$ for $30 \mathrm{~min}$ are shown in Figure 4. The grain size of the crystalline phase was estimated using the Scherrer formula as follows (Scherrer, 1918),

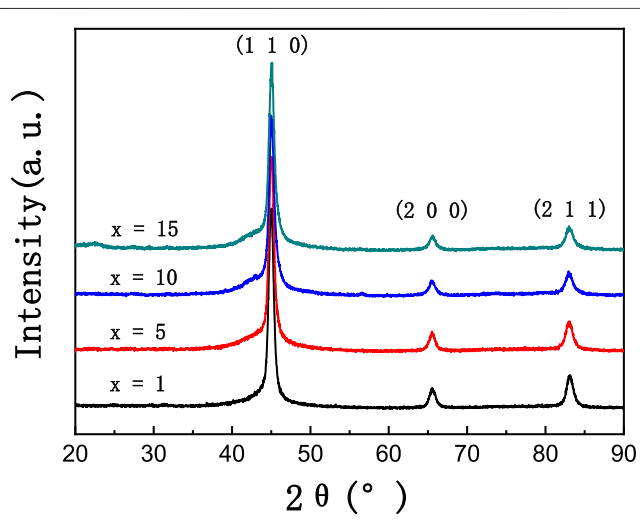

FIGURE 4 |XRD patterns of $\mathrm{Fe}_{66.8-x} \mathrm{CO}_{10} \mathrm{Ni}_{x} \mathrm{Cu}_{0.8} \mathrm{Nb}_{2.9} \mathrm{Si}_{11.5} \mathrm{~B}_{8}(\mathrm{x}=1,5$, 10,15 at\%) ribbons annealed at $838 \mathrm{~K}$ for $30 \mathrm{~min}$.

$$
D=\frac{K \lambda}{\beta \cos \theta}
$$

where $D$ is the grain size, $K$ is the Scherrer constant $(\sim 0.89), \lambda$ is the wavelength of the $\mathrm{X}$-ray, $\beta$ is the full width at half maximum (FWHM) of the diffraction peak, and $\theta$ is the Bragg angle. The crystallized volume fraction phase can be estimated by using the following equation (Langford, 1978; Verdon et al., 1998; Zhang et al., 1998; Cerqueira et al., 2000; Aronin et al., 2010):

$$
V_{c r}=\frac{I_{c r}}{I_{c r}+I_{a m}}
$$




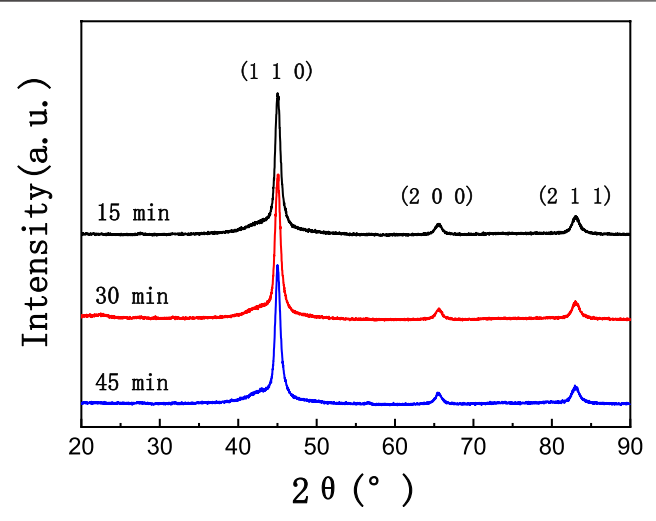

FIGURE 5 | XRD patterns of $\mathrm{Fe}_{51.8} \mathrm{Co}_{10} \mathrm{Ni}_{15} \mathrm{Cu}_{0.8} \mathrm{Nb}_{2.9} \mathrm{Si}_{11.5} \mathrm{~B}_{8}$ alloy ribbons annealed at $838 \mathrm{~K}$ for 15,30 , and $45 \mathrm{~min}$.

where $V_{c r}$ is the crystallized volume fraction, and $I_{c r}$ and $I_{a m}$ denote the integrated peak intensities of the crystalline and amorphous phases, respectively.

According to the $\mathrm{XRD}$ patterns, the first crystallization process of the $\mathrm{Fe}_{66.8-\mathrm{x}} \mathrm{Co}_{10} \mathrm{Ni}_{\mathrm{x}} \mathrm{Cu}_{0.8} \mathrm{Nb}_{2.9} \mathrm{Si}_{11.5} \mathrm{~B}_{8}$ ( $\mathrm{x}=1,5,10$, 15 at\%) samples is characterized by the precipitation of $\alpha-\mathrm{Fe}$ and some $\mathrm{a}-\mathrm{Fe}_{3} \mathrm{Si}$ crystalline phase. Additionally, Co and $\mathrm{Ni}$ atoms partially substitute the crystallographic positions of $\mathrm{Fe}$ atoms in the precipitated crystalline phases, leading to the formation of $\alpha-(\mathrm{Fe}, \mathrm{Ni}), \alpha-(\mathrm{Fe}, \mathrm{Co})$, and $\alpha-(\mathrm{Fe}, \mathrm{Co}, \mathrm{Ni})_{3} \mathrm{Si}$ phases with a bcc structure. Although there is an overlap area between the two crystallization temperatures at about $833 \mathrm{~K}$, there is no other phase but bcc. Maybe the content of the possibly existing phase is very small that we cannot find it through XRD results. The crystallized volume fraction is about $25 \%$, and the grain size is about $11-15 \mathrm{~nm}$. The main diffraction peak positions $(2 \theta)$ in XRD patterns for the $\mathrm{Fe}_{66.8-\mathrm{x}}$ $\mathrm{Co}_{10} \mathrm{Ni}_{\mathrm{x}} \mathrm{Cu}_{0.8} \mathrm{Nb}_{2.9} \mathrm{Si}_{11.5} \mathrm{~B}_{8}(\mathrm{x}=1,5,10,15$ at $\%)$ alloys are $44.92^{\circ}, 44.94^{\circ}, 45.03^{\circ}$, and $45.00^{\circ}$, respectively. The main diffraction peak positions $(2 \theta)$ and lattice constants for the $\alpha-\mathrm{Fe}, \alpha-\mathrm{Fe}_{3} \mathrm{Si}, \alpha-(\mathrm{Fe}, \mathrm{Ni})$, and $\alpha-(\mathrm{Fe}, \mathrm{Co})$ phases are $44.673^{\circ}$, $45.186^{\circ}, 44.645^{\circ}, 44.827^{\circ}$, and $2.8664,2.841,2.8681$, and $2.8570 \AA$, respectively. As the $\mathrm{Ni}$ content increases in the $\mathrm{Fe}_{66.8-\mathrm{x}} \mathrm{Co}_{10} \mathrm{Ni}_{\mathrm{x}} \mathrm{Cu}_{0.8} \mathrm{Nb}_{2.9} \mathrm{Si}_{11.5} \mathrm{~B}_{8}$ alloys, the solubility of $\mathrm{Ni}$ and $\mathrm{Si}$ in the crystalline phases increases during the crystallization process, causing severer lattice distortion. During the amorphous-to-crystalline transformation process, a proportion of energy is consumed to compensate for the elevated lattice distortion energy, so the crystallization enthalpy of the first crystallization stage declines.

Based on the random anisotropy model (Herzer, 1989), the magnetic anisotropy is mainly determined by the grain size $(D)$ and the crystallized volume fraction $(\chi)$. Specifically, magnetic anisotropy is positively correlated with grain size. The corresponding quantitative correlation can be expressed as below:

$$
\langle K\rangle=\left|K_{1}\right| \cdot \chi^{2}\left(D / L_{0}\right)^{6}
$$

where $\langle K\rangle$ is the effective anisotropy constant, $K_{1}$ is the magnetic anisotropy constant, and $L_{0}$ denotes the exchange length. The coercivity $H_{c}$ and initial permeability $\mu_{i}$ can be expressed as the following equations:

$$
\begin{aligned}
H_{c} & =P_{c} \frac{\langle K\rangle}{J_{s}} \\
\mu_{i} & =P_{c} \frac{J_{s}^{2}}{\mu_{0}\langle K\rangle}
\end{aligned}
$$

where $P_{c}$ is a dimensionless constant, $J_{s}$ is the saturation magnetic polarization of the material, and $\mu_{0}$ is the vacuum permeability. The rise in $H_{c}$ of soft magnetic alloys is mainly due to the increment in grain size.

The XRD patterns of the $\mathrm{x}=15$ alloy ribbons annealed at $838 \mathrm{~K}$ for 15,30 , and $45 \mathrm{~min}$ are shown in Figure 5. The crystallized volume fractions of the samples shown in Figure 5 are all about $25 \%$, while the corresponding grain size is $11-15 \mathrm{~nm}$. The crystalline phases are consistent with the previous analysis. So, the reason for the sharp increase in $H_{c}$ of the alloy annealed for $45 \mathrm{~min}$ is not caused by the increase in grain size. The diffraction peak positions and the lattice constant of the ribbons which were annealed for 15,30 , and $45 \mathrm{~min}$ are $44.980^{\circ}, 45.000^{\circ}$, and $44.960^{\circ}$ and $2.8478,2.8466$, and $2.8490 \AA$, respectively. Therefore, the drastic increase in coercivity is not caused by the difference in the degree of lattice distortion, either.

The theory proposed by Luborsky (Luborsky et al., 1976) suggests that the origin of the induced anisotropy $K_{u}$ in the amorphous alloys is the atomic pairing orientation, which is the same as that of the crystalline material. Since the crystallization process is a thermal activation process, the coupling orientation of $(\mathrm{Fe}, \mathrm{Ni}$ ) atoms would be enhanced as the annealing time increases. The magnetic anisotropy was enhanced then. The rise in $H_{c}$ could be ascribed to the enhanced magnetic anisotropy or the change in magnetic domain structure after the enhancement magnetic anisotropy.

The permeability-vs.-frequency curves of $\mathrm{Fe}_{66.8-\mathrm{x}}$ $\mathrm{Co}_{10} \mathrm{Ni}_{\mathrm{x}} \mathrm{Cu}_{0.8} \mathrm{Nb}_{2.9} \mathrm{Si}_{11.5} \mathrm{~B}_{8}(\mathrm{x}=1,5,10,15$ at\%) alloy cores which were annealed at $838 \mathrm{~K}$ for $30 \mathrm{~min}$ are shown in Figure 6. With the increase in $\mathrm{Ni}$ content, the initial permeability of the alloy becomes lower and the magnetic anisotropy is enhanced. The decay of relative initial magnetic

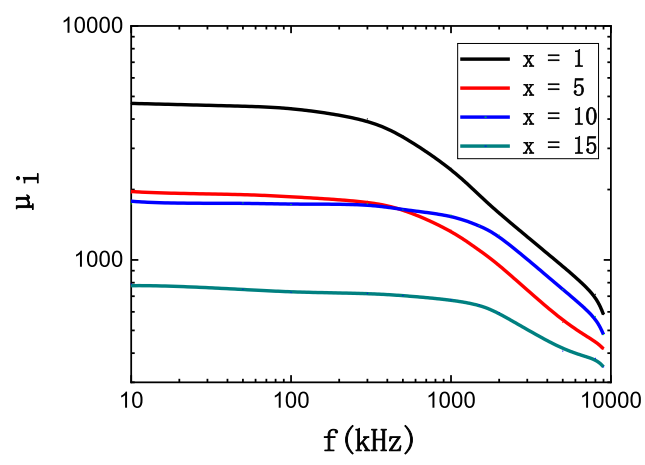

FIGURE 6 | The permeability-frequency curves of $\mathrm{Fe}_{66.8-x}$ $\mathrm{Co}_{10} \mathrm{Ni}_{x} \mathrm{Cu}_{0.8} \mathrm{Nb}_{2.9} \mathrm{Si}_{11.5} \mathrm{~B}_{8}(\mathrm{x}=1,5,10,15$ at\%) alloy cores. 

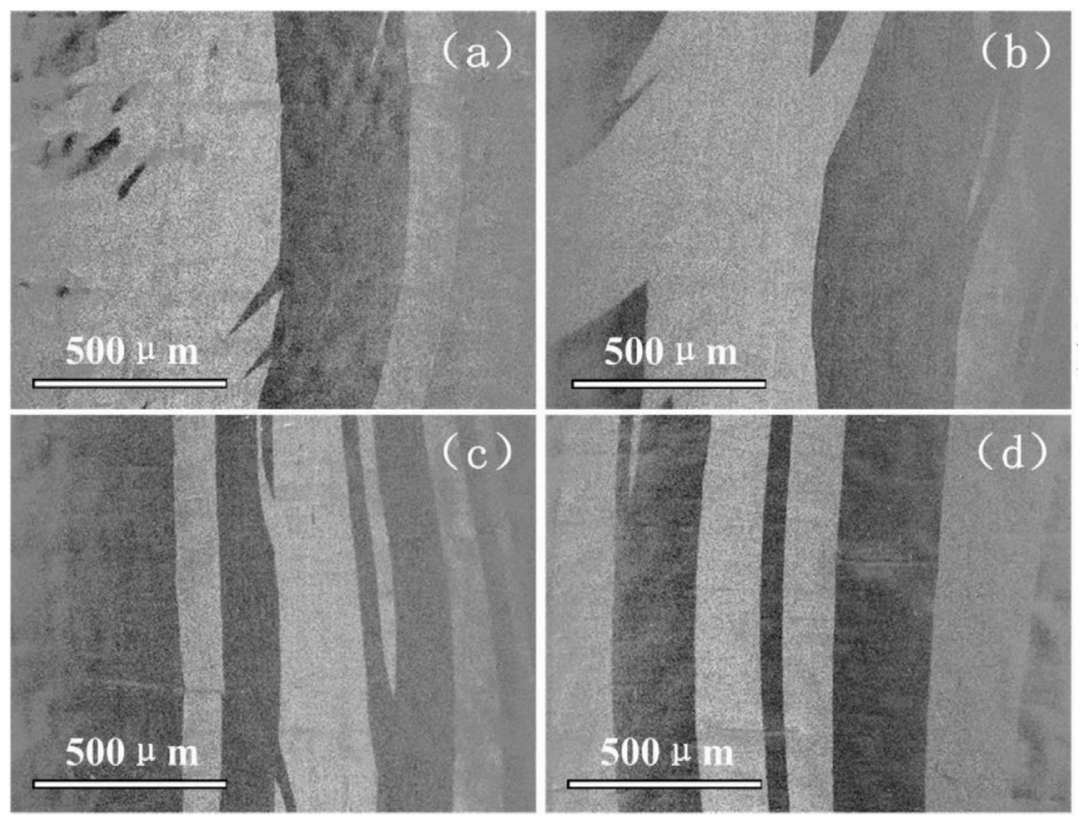

Ribbon width direction Easy magnetization axis

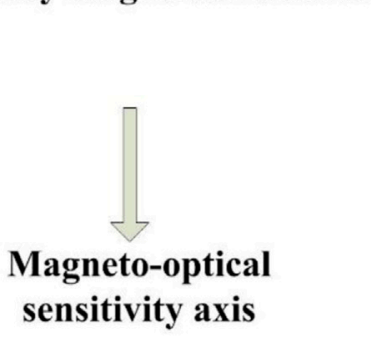

FIGURE 7 | (A) alloy of $x=1 \%$; (B) alloy of $x=5 \%$; (C) alloy of $x=10 \%$; (D) alloy of $x=15 \%$.

permeability became slower with the increase in frequency. The permeability of the alloy with a Ni content of $10 \%$ is about 2,000 , and the magnetic field induced $K_{u}$ is about $225 \mathrm{~J} / \mathrm{m}^{3}$. The permeability attenuation of these alloys was $47.8 \%, 35.2 \%$, $19.2 \%$, and $10.2 \%$ from 10 to $1,000 \mathrm{kHz}$ for the alloy with $\mathrm{Ni}$ content of $1 \%, 5 \%, 10 \%$, and $15 \%$, respectively. These results agree with the previous work by Ohnuma in Ref. (Herzer, 1994b) that, with the increase of $K_{u}$, the alloy exhibits more excellent permeability-vs.-frequency characteristics in the highfrequency band.

The domain structures of $\mathrm{Fe}_{66.8-\mathrm{x}} \mathrm{Co}_{10} \mathrm{Ni}_{\mathrm{x}} \mathrm{Cu}_{0.8} \mathrm{Nb}_{2.9} \mathrm{Si}_{11.5} \mathrm{~B}_{8}(\mathrm{x}$ $=1,5,10,15$ at\%) alloy ribbons annealed at $838 \mathrm{~K}$ for $30 \mathrm{~min}$ are shown in Figure 7. The double arrow line in Figure 7 denotes the width direction of the ribbon, which is parallel to the direction of the transverse magnetic field during annealing. The single arrow line is parallel to the orientation of the polarized light in the magneto-optical Kerr microscope. The light-colored magnetic domains are oriented in the same direction as the polarized light, while the dark magnetic domains are in the opposite direction of the polarized light. It can be concluded from the figure that the size of the magnetic domain decreases when the magnetic anisotropy intensity becomes stronger with the increase in the $\mathrm{Ni}$ content. The parallelism between the magnetic domain and the direction of the applied magnetic field becomes stronger. The local magnetic domain structure becomes more uniformly distributed. From the perspective of technical magnetization, the magnetic domain structure inside the material because the sum of the different energies tends to be minimized. Moreover, the corresponding energies can be categorized as the exchange energy, the magneto-elastic energy, the magneto-crystalline anisotropy, the demagnetizing field energy, and the applied magnetic field energy. This result agrees with the work by
Herzer (Herzer et al., 2011) that combines the domain structure and creep-induced $K_{u}$.

The changing process of $\mathrm{x}=10 \%$ alloy's domain structure during the whole magnetization process is shown in Figure 8. The direction distribution and test method of the magnetic domain structure photo are the same as those in Figure 7. The magnetic domain structure in each magnetized state is shown in the photograph indicated by the arrow in the figure. The magnetic domain of the alloy ribbon is fine $90^{\circ}$ structure, and the whole magnetization process is basically a reversible movement of the domain walls. According to the magnetization theory of soft magnetic materials, the magnetization process can be separated into five steps (Tahara and Sugeno, 1973; Iványi, 1997). First is the initial magnetization $\left(\mu_{i}\right)$, or the so-called linear magnetization region, where $B$ varies linearly with $H$. Second is the Rayleigh region, where the magnetization process is no longer linear. Third is the maximum permeability region, where $B$ increases sharply with $H$. Fourth is the near saturation region. Fifth is the paramagnetic region. In the magnetization process of $\mathrm{Fe}_{61.8} \mathrm{Co}_{10} \mathrm{Ni}_{5} \mathrm{Cu}_{0.8} \mathrm{Nb}_{2.9} \mathrm{Si}_{11.5} \mathrm{~B}_{8}$ and $\mathrm{Fe}_{56.8} \mathrm{Co}_{10} \mathrm{Ni}_{10} \mathrm{Cu}_{0.8} \mathrm{Nb}_{2.9} \mathrm{Si}_{11.5} \mathrm{~B}_{8}$ alloy ribbons, the first region is very big, and the second to fourth regions become very small. So, the magnetization process is kept linear until saturation.

For the $\mathrm{Fe}_{51.8} \mathrm{Co}_{10} \mathrm{Ni}_{15} \mathrm{Cu}_{0.8} \mathrm{Nb}_{2.9} \mathrm{Si}_{11.5} \mathrm{~B}_{8}$ alloy ribbon, more $\mathrm{Ni}$ elements may be entrapped in the $\alpha-(\mathrm{Fe})$ and $\alpha-(\mathrm{Fe})_{3} \mathrm{Si}$ crystallization phases to replace the $\mathrm{Fe}$ atom position during the heat treatment. It will result in a more serious lattice distortion, so the energy of the alloy system increases. In addition, the addition of the $\mathrm{Ni}$ element increases the number of magnetic interaction $(\mathrm{Fe}, \mathrm{Ni})$ atom pairs in the alloy and enhances the magnetic anisotropy. In order to reduce the energy 


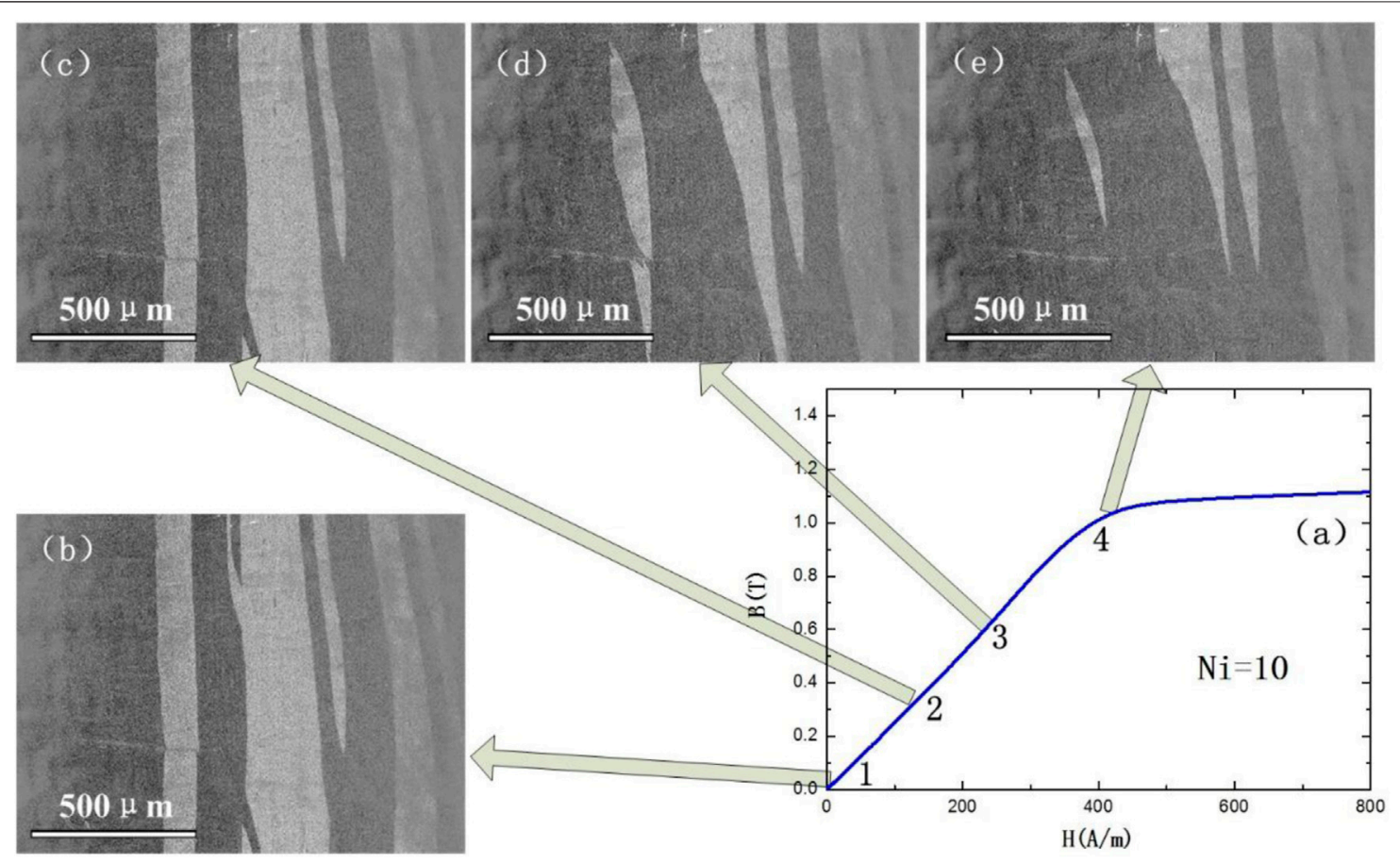

FIGURE 8 | Changes of the domain structure during the magnetization of $\mathrm{Fe}_{56.8} \mathrm{Co}_{10} \mathrm{Ni}_{10} \mathrm{Cu}_{0.8} \mathrm{Nb}_{2.9} \mathrm{Si}_{11.5} \mathrm{~B}_{8}$ alloy ribbon which was annealed at $838 \mathrm{~K}$ for 30 min. (A) Magnetization curve, (B) magnetization state 1, (C) magnetization state 2, (D) magnetization state 3, and (E) magnetization state 4.

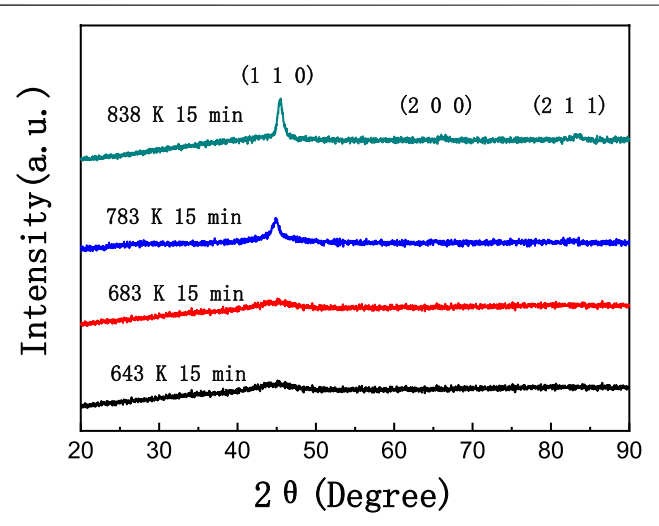

FIGURE 9 | XRD patterns of $\mathrm{Fe}_{51.8} \mathrm{Co}_{10} \mathrm{Ni}_{15} \mathrm{Cu}_{0.8} \mathrm{Nb}_{2.9} \mathrm{Si}_{11.5} \mathrm{~B}_{8}$ alloy ribbons annealed at $643,683,783$, and $838 \mathrm{~K}$ for $15 \mathrm{~min}$.

of the alloy, the magnetic field size of the soft magnetic alloy becomes smaller. This makes the $\mathrm{B}-\mathrm{H}$ loop of the alloy with strong magnetic anisotropy show poor linearity, and its coercivity and remanence are larger.

Since the soft magnetic properties of the $\mathrm{Fe}_{51.8} \mathrm{Co}_{10} \mathrm{Ni}_{15} \mathrm{Cu}_{0.8} \mathrm{Nb}_{2.9} \mathrm{Si}_{11.5} \mathrm{~B}_{8}$ alloy are very poor, some further heat treatment was applied to the cores. The deterioration of the coercivity property was originated in the distortion of the lattice. It was assumed that the distortion could be reduced by the decrease in the crystallization degree. We chose a temperature that is higher than the crystallization temperature

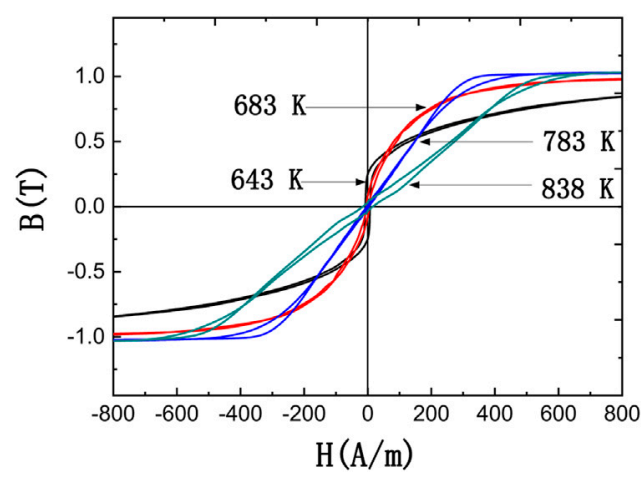

FIGURE 10 | B-H loops of $\mathrm{Fe}_{66.8-x} \mathrm{Co}_{10} \mathrm{Ni}_{x} \mathrm{Cu}_{0.8} \mathrm{Nb}_{2.9} \mathrm{Si}_{11.5} \mathrm{~B}_{8}(\mathrm{x}=15$ at $\%)$ cores annealed at $643,683,783$, and $838 \mathrm{~K}$ for $15 \mathrm{~min}$.

and definitely lower than the overlap region. Moreover, some other temperatures that are lower than the crystallization temperature were set. The heat treatment temperatures were 783, 683, and $643 \mathrm{~K}$ then, and the heat treatment time was $15 \mathrm{~min}$. The heat treatment was finished when the furnace was cooled to $473 \mathrm{~K}$, and the transverse magnetic field of 400 Oe was applied. The $\mathrm{XRD}$ patterns of the $\mathrm{Fe}_{51.8} \mathrm{Co}_{10} \mathrm{Ni}_{15} \mathrm{Cu}_{0.8} \mathrm{Nb}_{2.9} \mathrm{Si}_{11.5} \mathrm{~B}_{8}$ alloy ribbons after heat treatment are shown in Figure 9. The crystallization temperature of the alloy is $750 \mathrm{~K}$, and the first crystallization peak temperature is $777 \mathrm{~K}$. Some $\alpha$-Fe-crystallized phases were formed after the heat treatment at $783 \mathrm{~K}$ for $15 \mathrm{~min}$. After 
TABLE 3 | Properties of the different temperature-annealed

$\mathrm{Fe}_{51.8} \mathrm{Co}_{10} \mathrm{Ni}_{15} \mathrm{Cu}_{0.8} \mathrm{Nb}_{2.9} \mathrm{Si}_{11.5} \mathrm{~B}_{8}$ alloy.

\begin{tabular}{lcccc}
\hline Properties & $\mathbf{8 3 8} \mathbf{K}$ & $\mathbf{6 4 3} \mathbf{K}$ & $\mathbf{6 8 3} \mathbf{K}$ & $\mathbf{7 8 3} \mathbf{~ K}$ \\
\hline $\mathrm{H}_{\mathrm{c}}(\mathrm{A} / \mathrm{m})$ & 15.81 & 7.29 & 4.11 & 3.63 \\
$\mathrm{~B}_{\mathrm{r}}(\mathrm{mT})$ & 27.6 & 250.9 & 80.7 & 12.2 \\
$\mu_{\mathrm{i}}$ & 1,310 & 13,780 & 8,090 & 2,560 \\
$\mathrm{~K}_{\mathrm{u}}\left(\mathrm{J} / \mathrm{m}^{3}\right)$ & 232 & - & - & 180
\end{tabular}

calculation, the crystallization ratio is less than 5\%. Both 683 and $643 \mathrm{~K}$ were subjected to stress relief annealing, and the alloy ribbons possess a typical amorphous structure after heat treatment.

The B-H loops of these $\mathrm{Fe}_{51.8} \mathrm{Co}_{10} \mathrm{Ni}_{15} \mathrm{Cu}_{0.8} \mathrm{Nb}_{2.9} \mathrm{Si}_{11.5} \mathrm{~B}_{8}$ alloy are shown in Figure 10. The $\mu_{i}, H_{c}$, and $B_{r}$ properties are listed in Table 3. With the increase in heat treatment temperature, the linearity of the B-H loop gradually increased; meanwhile, the remanence and coercivity decreased. When the heat treatment temperature rises from 643 to 783, the coercivity of the alloy decreases from 7.29 to $3.63 \mathrm{~A} / \mathrm{m}$, and the remanence is reduced from 250.9 to $12.2 \mathrm{mT}$. However, when the heat treatment temperature increased to $838 \mathrm{~K}$, the coercivity of the alloy increased to $15.81 \mathrm{~A} / \mathrm{m}$, and remanence increased to $27.6 \mathrm{mT}$. It seems that the trace crystallization is beneficial to obtain excellent soft magnetic properties for the Fe-based alloy with high content of Ni. To obtain better soft magnetic properties, it can be summarized as the following: the higher the Ni content, the lower the heat treatment temperature required.

\section{SUMMARY}

The crystallization behavior, microstructure, soft magnetic properties, and domain structure for $\mathrm{Fe}_{66.8-\mathrm{x}} \mathrm{Co}_{10} \mathrm{Ni}_{\mathrm{x}} \mathrm{Cu}_{0.8} \mathrm{Nb}_{2.9} \mathrm{Si}_{11.5} \mathrm{~B}_{8}$ alloys with the Ni content ranging from $\mathrm{x}=1$ to $\mathrm{x}=15$ have been systemically studied, and results are summarized as follows:

1. The increment of the $\mathrm{Ni}$ content results in the decline of the crystallization temperature of the secondary crystallization phase and decreases the thermal stability of the $a$-Fe phase.

\section{REFERENCES}

Agudo, P., and Vázquez, M. (2005). Influence of Ni on the Structural and Magnetic Properties of $\mathrm{Ni}_{x} \mathrm{Fe}_{73.5-\mathrm{x}} \mathrm{Si}_{13.5} \mathrm{~B}_{9} \mathrm{Nb}_{3} \mathrm{Cu}_{1}(0 \leqslant \mathrm{x} \leqslant 25)$ Alloys. J. Appl. Phys. 97, 023901. doi:10.1063/1.1825633

Aronin, A., Abrosimova, G., Matveev, D., and Rybchenko, O. (2010). Structure and Properties of Nanocrystalline. Rev. Adv. Mater. Sci. 25, 52-57.

Cerqueira, M. F., Ferreira, J. A., and Adriaenssens, G. J. (2000). Structural Studies and Influence of the Structure on the Electrical and Optical Properties of Microcrystalline Silicon Thin Films Produced by RF Sputtering. Thin Solid Films 370, 128-136. doi:10.1016/s0040-6090(00)00950-0

Chen, F. G., Wang, Y. G., Miao, X. F., Hong, H., and Bi, K. (2013). Nanocrystalline Fe83P16Cu1 Soft Magnetic alloy Produced by Crystallization of its Amorphous Precursor. J. Alloys Compd. 549, 26-29. doi:10.1016/j.jallcom.2012.09.072

Fujimori, H., Morita, H., Obi, Y., and Ohta, S. (1977). "On the Magnetically Induced Anisotropy in Amorphous Ferromagnetic Alloys," in Amorphous
The temperature interval between the two crystallization processes is drastically reduced from 165 to $119 \mathrm{~K}$ when the $\mathrm{Ni}$ content increases from $\mathrm{x}=1$ to $\mathrm{x}=15$.

2. With the increase in $\mathrm{Ni}$ content, the magnetic anisotropy of the alloy is enhanced. However, when the Ni content is $\geq 15 \%$, the coercivity and remanence properties of the alloy deteriorate sharply. The low coercivity and remanence properties can be obtained by reducing the heat treatment temperature, and the $\mathrm{B}-\mathrm{H}$ loop linearity of the alloy is improved.

3. A large magnetic field-induced $K_{u}$ of $225 \mathrm{~J} / \mathrm{m}^{3}$ can be obtained through optimized annealing, and the $\mathrm{Fe}_{56.8} \mathrm{Co}_{10} \mathrm{Ni}_{10} \mathrm{Cu}_{0.8} \mathrm{Nb}_{2.9} \mathrm{Si}_{11.5} \mathrm{~B}_{8} \quad$ nanocrystalline alloy exhibits a linear $\mathrm{B}-\mathrm{H}$ loop and its initial permeability $\mu \mathrm{i}$ is as low as 2,000. It makes the alloy a promising material in the field of common mode chokes or current transformers, where the ability to resist the direct current is necessary.

\section{DATA AVAILABILITY STATEMENT}

The original contributions presented in the study are included in the article/Supplementary Material; further inquiries can be directed to the corresponding author.

\section{AUTHOR CONTRIBUTIONS}

$\mathrm{ZL}$, the first person to complete the thesis work. KY, provided ideas for this work and finished the thesis together. TL, provided materials to finish the experimental works. XL, participated the testing work. SW, provided suggestions for the completion of the thesis.

\section{FUNDING}

This work was supported by the National Key Basic Research and Development Program (Grant No. 2016YFB0300502), National Natural Science Foundation of China (11875270), and Youth Innovation Promotion Association CAS (2018015).

Magnetism II. Editors R. A. Levy and R. Hasegawa (New York: Prenum), 393-402. doi:10.1007/978-1-4613-4178-9_37

Hasegawa, R. (2006). Advances in Amorphous and Nanocrystalline Magnetic Materials. J. Magn. Magn. Mater. 304, 187-191. doi:10.1016/ j.jmmm.2006.02.119

Hasegawa, R. (2004). Applications of Amorphous Magnetic Alloys. Mater. Sci. Eng. A. 375, 90-97. doi:10.1016/j.msea.2003.10.258

Herzer, G., Budinsky, V., and Polak, C. (2011). Magnetic Properties of FeCuNbSiB Nanocrystallized by Flash Annealing under High Tensile Stress. Phys. Status Solidi B 248, 2382-2388. doi:10.1002/pssb.201147088

Herzer, G. (1994). Creep Induced Magnetic Anisotropy in Nanocrystalline Fe-CuNb-Si-B Alloys. IEEE Trans. Magn. 30, 4800-4802. doi:10.1109/20.334226

Herzer, G. (1989). Grain Structure and Magnetism of Nanocrystalline Ferromagnets. IEEE Trans. Magn. 25, 3327-3329. doi:10.1109/20.42292

Herzer, G. (1994). Magnetic Field Induced Anisotropy in Nanocrystalline Fe Cu Nb Si B Alloys. Mater. Sci. Eng. A 181-182, 876-879. doi:10.1016/09215093(94)90760-9 
Herzer, G. (2013). Modern Soft Magnets: Amorphous and Nanocrystalline Materials. Acta Materialia 61, 718-734. doi:10.1016/j.actamat.2012.10.040

Herzer, G., Vazquez, M., Knobel, M., Zhukov, A., Reininger, T., Davies, H. A., et al. (2005). Round Table Discussion: Present and Future Applications of Nanocrystalline Magnetic Materials. J. Magnetism Magn. Mater. 294, 252-266. doi:10.1016/j.jmmm.2005.03.042

Iványi, A. (1997). Hysteresis Models in Electromagnetic Computation. Budapest, Hungary: University of Pécs, Book, Akadémiai Kiadó.

Kubota, T., Makino, A., and Inoue, A. (2011). Low Core Loss of Fe85Si2B8P4Cu1 Nanocrystalline Alloys with High Bs and B800. J. Alloys Compd. 509, S416-S419. doi:10.1016/j.jallcom.2010.11.012

Langford, J. I. (1978). A Rapid Method for Analysing the Breadths of Diffraction and Spectral Lines Using the Voigt Function. J. Appl. Cryst. 11, 10-14. doi:10.1107/s0021889878012601

Li, J.-F., Liu, X., Zhao, S.-F., Ding, H.-Y., and Yao, K.-F. (2015). Fe-based Bulk Amorphous Alloys with Iron Contents as High as 82at\%. J. Magnetism Magn. Mater. 386, 107-110. doi:10.1016/j.jmmm.2015.03.070

Li, Z., Wang, A., Chang, C., Wang, Y., Dong, B., and Zhou, S. (2014). Synthesis of FeSiBPNbCu Nanocrystalline Soft-Magnetic Alloys with High Saturation Magnetization. J. Alloys Compd. 611, 197-201. doi:10.1016/ j.jallcom.2014.04.223

Luborsky, F. E., Becker, J. J., Lander, G. H., and Rhyne, J. J. (1976). "Kinetics of reorientation of magnetically induced anisotropy in amorphous Ni40Fe40P14B6," in AIP Conference Proceedings 29, 209-210. doi:10.1063/ 1.30588

Makino, A., He Men, H., Kubota, T., Yubuta, K., and Inoue, A. (2009). New Excellent Soft Magnetic FeSiBPCu Nanocrystallized Alloys with High $\$ B_{-}\{s\} \$$ of $1.9 \mathrm{~T}$ from Nanohetero-Amorphous Phase. IEEE Trans. Magn. 45, 4302-4305. doi:10.1109/tmag.2009.2023862

Makino, A., Inoue, A., and Masumoto, T. (1995). Soft Magnetic Properties of Nanocrystalline $\mathrm{Fe} \mathrm{M} \mathrm{B(M} \mathrm{Zr,} \mathrm{Hf,} \mathrm{Nb)} \mathrm{Alloys} \mathrm{with} \mathrm{High} \mathrm{Magnetization.}$ Nanostructured Mater. 6, 985-988. doi:10.1016/0965-9773(95)00226-x

Ohnuma, M., Ping, D. H., Abe, T., Onodera, H., Hono, K., and Yoshizawa, Y. (2003). Optimization of the Microstructure and Properties of Co-substituted Fe-Si-B-Nb-Cu Nanocrystalline Soft Magnetic Alloys. J. Appl. Phys. 93, 9186-9194. doi:10.1063/1.1569396

Ohta, M., and Yoshizawa, Y. (2007). New High-BsFe-Based Nanocrystalline Soft Magnetic Alloys. Jpn. J. Appl. Phys. 46, L477-L479. doi:10.1143/jjap.46.1477

Petzold, J. (2002). Advantages of Softmagnetic Nanocrystalline Materials for Modern Electronic Applications. J. Magnetism Magn. Mater. 242-245, 84-89. doi:10.1016/s0304-8853(01)01206-9

Scherrer, P. (1918). Bestimmung der Größe und der inneren Struktur von Kolloidteilchen mittels Röntgenstrahlen. Nachr. Ges. Wiss. Goettingen, Math.-Phys. Kl. 26, 98.

Shi, L., Hu, X., Li, Y., Yuan, G., and Yao, K. (2021). The Complementary Effects of $\mathrm{Fe}$ and Metalloids on the Saturation Magnetization of Fe-Based Amorphous Alloys. Intermetallics 131, 107116. doi:10.1016/j.intermet.2021.107116
Shi, L., and Yao, K. (2020). Composition Design for Fe-Based Soft Magnetic Amorphous and Nanocrystalline Alloys with High Fe Content. Mater. Des. 189, 108511. doi:10.1016/j.matdes.2020.108511

Tahara, Y., and Sugeno, T. (1973). A Theory of Magnetic After-Effect for the Irreversible Magnetization Process in Rayleigh Region. Phys. Stat. Sol. (B) 55, 385-398. doi:10.1002/pssb.2220550140

Urata, A., Matsumoto, H., Yoshida, S., and Makino, A. (2011). Fe-B-P-Cu Nanocrystalline Soft Magnetic Alloys with High Bs. J. Alloys Compd. 509, S431-S433. doi:10.1016/j.jallcom.2010.12.104

Verdon, C., Karimi, A., and Martin, J.-L. (1998). A Study of High Velocity Oxy-Fuel Thermally Sprayed Tungsten Carbide Based Coatings. Part 1: Microstructures. Mater. Sci. Eng. A 246, 11-24. doi:10.1016/s0921-5093(97)00759-4

Yoshizawa, Y., Fujii, S., Ping, D. H., Ohnuma, M., and Hono, K. (2003). Magnetic Properties of Nanocrystalline FeMCuNbSiB Alloys (M: Co, Ni). Scripta Materialia 48, 863-868. doi:10.1016/s1359-6462(02)00611-5

Yoshizawa, Y., Oguma, S., and Yamauchi, K. (1988). New Fe-based Soft Magnetic Alloys Composed of Ultrafine Grain Structure. J. Appl. Phys. 64, 6044-6046. doi:10.1063/1.342149

Yoshizawa, Y., Yamauchi, K., Yamane, T., and Sugihara, H. (1988). Common Mode Choke Cores Using the New Fe-based Alloys Composed of Ultrafine Grain Structure. J. Appl. Phys. 64, 6047-6049. doi:10.1063/ 1.342150

Zhang, X. Y., Zhang, F. X., Zhang, J. W., Yu, W., Zhang, M., Zhao, J. H., et al. (1998). Influence of Pressures on the Crystallization Process of an Amorphous Fe73.5Cu1Nb3Si13.5B9 alloy. J. Appl. Phys. 84, 1918-1923. doi:10.1063/ 1.368319

Conflict of Interest: TL was employed by the company China Iron and Steel Research Institute Group, Advanced Technology and Materials Co., Ltd.

The remaining authors declare that the research was conducted in the absence of any commercial or financial relationships that could be construed as a potential conflict of interest.

Publisher's Note: All claims expressed in this article are solely those of the authors and do not necessarily represent those of their affiliated organizations, or those of the publisher, the editors, and the reviewers. Any product that may be evaluated in this article, or claim that may be made by its manufacturer, is not guaranteed or endorsed by the publisher.

Copyright (c) $2022 \mathrm{Li}, \mathrm{Yao}, \mathrm{Liu}, \mathrm{Li}$ and Wang. This is an open-access article distributed under the terms of the Creative Commons Attribution License (CC $B Y$ ). The use, distribution or reproduction in other forums is permitted, provided the original author(s) and the copyright owner(s) are credited and that the original publication in this journal is cited, in accordance with accepted academic practice. No use, distribution or reproduction is permitted which does not comply with these terms. 